\title{
An Extra Small Metacentric Chromosome in Association with Multiple Congenital Abnormalities*
}

\author{
W. H. FINLEY, S. C. FINLEY, and D. MONSKY \\ From the Laboratory of Medical Genetics, University of Alabama in Birmingham, and the Diagnostic Clinic for Children, \\ Montgomery, Alabama 35233, USA
}

Excess genetic material in the form of a small metacentric chromosome, often smaller than a member of the $G$ group, has been reported in a number of cases (Ilberry, Lee, and Winn, 1961; Frøland, Holst, and Terslev, 1963; Uchida et al, 1964; Taft, Dodge, and Atkins, 1965; Gustavson, Atkins, and Patricks, 1964, Crawfurd and Lele, 1965; Tamburro and Johnson, 1966; Gamstorp, Håkansson, and Lagergren, 1966; Ferrante et al, 1968). In some patients with this small extra chromosome there have been suggestions of which chromosome part was in triplicate, as in the cases described by Stevenson, Patterson, and Goodman (1966), with an isochromosome of the short arms of $D$, with a C/D translocation (Insley, Rushton, and Jones, 1968), with a G/G translocation (Mukerjee and Burdette, 1966) and with incomplete D trisomy (Ishmael and Laurence, 1965). Also a phenotypically normal mother and her son with oligospermia were found to have an extra small metacentric chromosome (Smith et al, 1965).

In the majority of the cases reported, it has not been concluded which chromosome or chromosome part is in triplicate, but some of the patients with the abnormal chromosome have had features suggestive of Down's syndrome (Ilberry et al, 1961; Dent, Edwards, and Delhanty, 1963; Gustavson et al, 1964; Dekaban and Zelson, 1968).

A child with mental retardation and multiple congenital abnormalities in association with an extra metacentric chromosome which is smaller than a member of the $G$ group is reported here. No conclusion is reached about the origin of the extra chromosome material.

\footnotetext{
Received 7 December 1970.

* Aided by project 905, Maternal and Child Health Service, Health Services and Mental Health Administration, Department of Health, Education, and Welfare, US Public Health Service and from NIH grants 5501 FR5349 and 5501FR5300.
}

\section{Case Report}

An 8-year old Caucasian female (Fig. 1) was referred for evaluation of mental retardation in association with congenital malformations. The mother was 36 years of age at the time of birth of this child who was born prematurely weighing $2040 \mathrm{~g}$. No congenital malformations are obvious in either parent. The propositus first sat up at 22 months of age and first walked at 3 years of age. She weighed $20.4 \mathrm{~kg}$ at 8 years of age (less than Ioth centile on Stuart scale) and her height of $118.1 \mathrm{~cm}$ was also less than 10th centile. Physical examination showed microcephaly with skull asymmetry, small ears with undeveloped pinnae, an epicanthus on the right, marked blepharitis, confluent eyebrows, high arched palate, clinodactyly, flexion of left fifth finger, and scoliosis. By 9 years of age, the scoliosis was marked and there was a beginning cervical kyphosis. Hearing examination did not reveal abnormalities. Psychological evaluation indicates severe mental retardation. Speech development at age 8 years was markedly retarded.

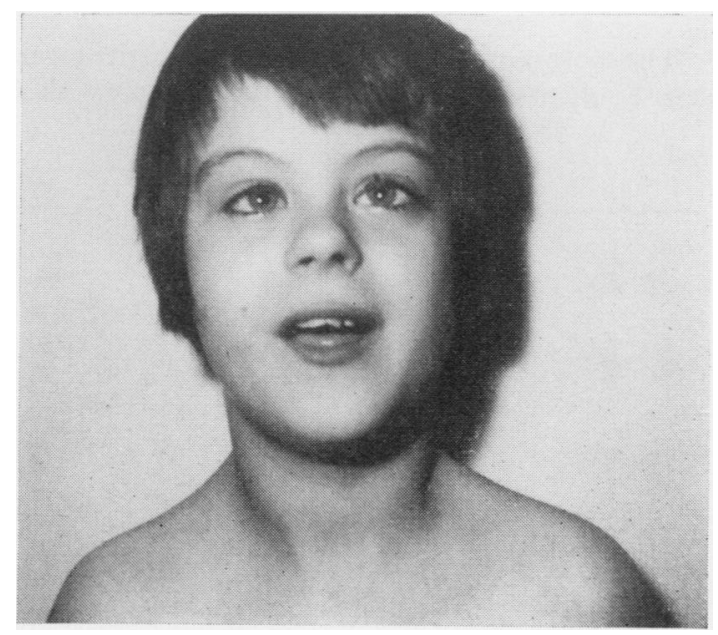

Fig. 1. The proposita. 
TABLE

GENETIC MARKER STUDIES

\begin{tabular}{|c|c|c|c|c|c|c|c|c|c|c|c|}
\hline & ABO & $M N$ & $\mathbf{R h}$ & $\mathbf{K}$ & $P_{1}$ & Fy ${ }^{a}$ & $L e^{b}$ & $\mathrm{Hp}$ & $\operatorname{IgA}$ & $\operatorname{Ig} M$ & $\mathrm{IgG}$ \\
\hline $\begin{array}{l}\text { Proposita } \\
\text { Mother } \\
\text { Father }\end{array}$ & $\begin{array}{l}A_{1} \\
A_{1} \\
A_{2}\end{array}$ & $\begin{array}{l}\text { MN } \\
\mathbf{M}\end{array}$ & $\begin{array}{c}R^{1} \mathbf{r} \\
\mathbf{R}^{1} \mathbf{r} \\
\mathbf{r r}\end{array}$ & $\bar{z}$ & $\frac{+}{+}$ & $\begin{array}{l}+ \\
+ \\
+\end{array}$ & $\bar{t}$ & $\begin{array}{l}1-1 \\
1-1 \\
2-1\end{array}$ & $\begin{array}{l}140 \\
280 \\
155\end{array}$ & $\begin{array}{l}132 \\
210 \\
132\end{array}$ & $\begin{array}{l}1820 \\
1700 \\
1150\end{array}$ \\
\hline
\end{tabular}

Radiographic examination showed increase in the trabecular pattern of the ends of the long bones, curvature of distal radii with concavity towards ulna, coxa valga, delayed bone age, rudimentary right first rib, decreased size of iliac bones, and an additional epiphysis at the distal end of the first metacarpal bilaterally.

Cytogenetic Studies. In cells derived by culture of the peripheral leucocytes, the proposita was found to have a karyotype with 47 chromosomes. The extra chromosome appeared to be metacentric and to be smaller than the $\mathrm{G}$ chromosomes (Fig. 2). The arms of the abnormal chromosome were interpreted as being longer than the short arms of $\mathrm{G}$ chromosomes. Using autoradiography following tritiated thymidine addition to leucocyte cultures, the extra metacentric chromosome was labelled in 3 of 11 metaphase plates studied in detail. In 2 of the 3 plates all chromosomes were labelled except an $\mathrm{E}$ chromosome which was concluded to be either a 17 or 18 . In the other plates with 9 to 42 labelled chromosomes the extra metacentric was not labelled in any of the plates. Therefore, this extra metacentric chromosome appeared to replicate early in the $S$ phase of the cell cycle in those cells derived by culture of peripheral leucocytes. No satellites were observed on the extra chromosome in any of the 50 plates examined. Karyotypes of mother and father were interpreted as normal.

The Table shows the results of various genetic marker determinations.

\section{Discussion}

The most outstanding features of our patient were severe mental retardation, microcephaly, skull asymmetry, blepharitis, flexion of fifth finger, and scoliosis.

A comparison of the physical features of this patient with other reported patients with an apparently similar extra small metacentric chromosome does not permit the identification of this extra genetic material. The only conclusion from autoradiographic studies was that this metacentric chromosome replicated early in the $S$ phase of the cell cycle.

While the extra chromosome in this patient could not be identified as to origin the karyotype abnormality is likely the aetiology of this child's severe retardation. Perhaps reports of further cases and a comparison of individuals with unusual karyotypes could aid in better classification, diagnosis, and prognostic information in those children with previously undiagnosed multiple malformation syndromes.

\section{Summary}

An 8-year-old Caucasian female was found to have an extra metacentric chromosome in association with multiple congenital malformations. This nonsatellited chromosome was smaller than a G chromosome and replicated early. The patient's abnormal features included mental retardation, retardation in growth and development, microcephaly, small ears with undeveloped pinnae, epi-

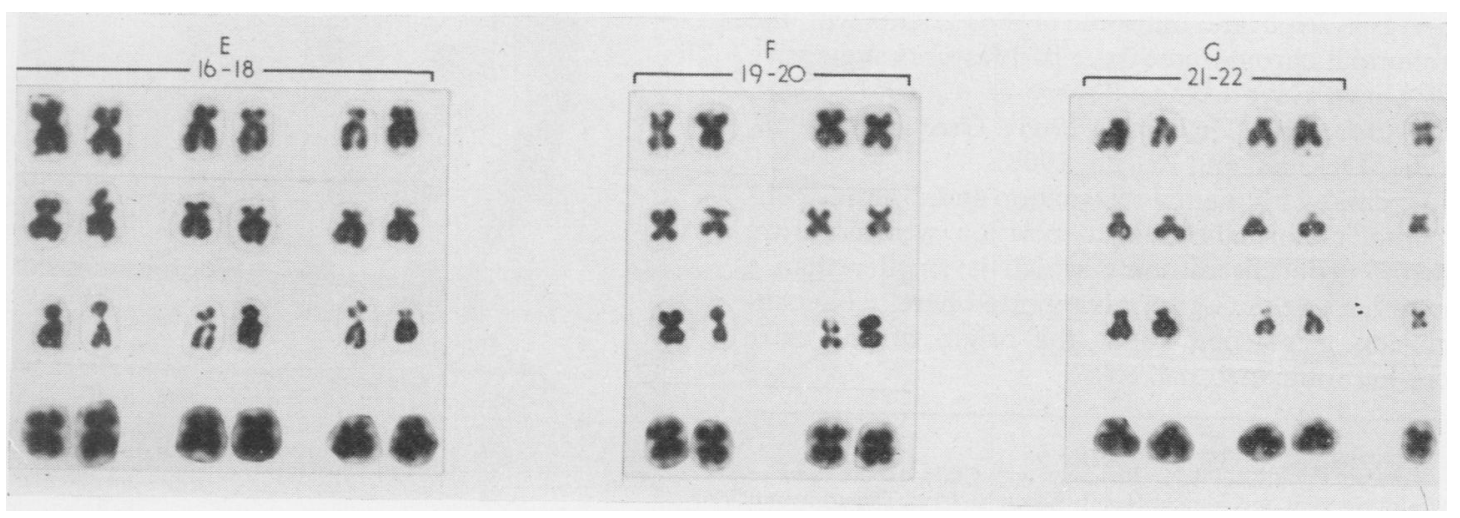

FiG. 2. E, F, and G chromosomes from 4 karyotypes of the proposita. The extra chromosomes are shown at the right. 
canthic fold, blepharitis, confluent eyebrows, high arched palate, clinodactyly, and scoliosis.

We wish to thank Dr June Shaw for the genetic marker studies and Dr Guy Hicks for the radiological examinations. We are grateful to $\mathrm{Mr}$ Kenneth Beil for assistance in the preparation of the manuscript.

\section{REFERENCES}

Crawfurd, M. D.'A. and Lele, K. P. (1965). A child with an extra small metacentric chromosome. Annals of Human Genetics, 29, 199-205.

Dekaban, A. S. and Zelson, J. (1968). Retardation in a child with an extra submetacentric chromosome fragment and partial mongolism. Fournal of Mental Deficiency Research, 12, 216-225.

Dent, T., Edwards, J. H., and Delhanty, J. D. A. (1963). A partial mongol. Lancet, 2, 484-487.

Ferrante, E., Bruni, L., Laurenti, F., and Cogliati Dezza, G. (1968), Parziole trisomia autosomica in soggetto affetto da ritardo mentale e lievi note dismorfiche. Minerva Pediatrica, 20, 522-529.

Frøland, A., Holst, G., and Terslev, E. (1963). Multiple anomalies associated with an extra small autosome. Cytogenetics, 2, 99-106.

Gamstorp, I. Håkansson, L., and Lagergren J. (1966). A case of

mental retardation with an additional small metacentric chromosome. Hereditas, Genetiskt Arkiv, 55, 266-272.
Gustavson, K.-H., Atkins, L., and Patricks, I. (1964). Diverse chromosomal anomalies in two siblings. Acta Paediatrica, 53, 371-387.

Ilberry, P. L. T., Lee, C. W. G., and Winn, S. M. (1961). Incomplete trisomy in a mongoloid child exhibiting minimal stigmata. Medical fournal of Australia, 48, 182-184.

Insley, J, Rushton, D. I., and Jones, H. W. E. (1968). An intersexual infant with an extra chromosome. Annales de Génétique, 11, 88-94.

Ishmael, J. and Laurence, K. M. (1965). A probable case of incomplete trisomy of a chromosome of the 13-15 group. fournal Medical Genetics, 2, 136-141.

Mukeriee, D and Burdette, W. J. (1966). A familial minute isochromosome. American fournal of Human Genetics, 18, 62-69.

Smith K. D., Steinberger, E., Steinberger, A., and Perloff, W. H. (1965). A familial centric chromosome fragment. Cytogenetics, 4, 219-226.

Stevenson, R. E., Patterson, R. B., and Goodman, H. O. (1966). Possible autosomal isochromosome in a malformed child. American fournal of Diseases of Children, 111, 327-332.

Taft, P. D., Dodge, P. R., and Atkins, L. (1965). Mental retardation and multiple congenital anomalies. American fournal of Diseases of Children, 109, 554-557.

Tamburro, R. F. and Johnson, C. E. (1966). An extra small metacentric chromosome in a female child. fournal Medical Genetics, 3, 295-297.

Uchida, I. A., Wang, H. C., Laxdal, O. E., Zaleski, W. A., and Duncan, B. P. (1964). Partial trisomy-deficiency syndrome resulting from a reciprocal translocation in a large kindred. Cytogenetics, 3, 81-96. 